\title{
PENGARUH PEMBERIAN MONOSODIUM GLUTAMATE TERHADAP PERTUMBUHAN TANAMAN CABAI RAWIT (Capsicum frutescens L.)
}

\author{
Nadela Agitaria ${ }^{1}$, Marmaini $^{2}$, Ita Emilia $^{3}$ \\ ${ }^{1}$ Mahasiswa Program Studi Biologi, Fakultas Matematika dan Ilmu Pengetahuan Alam \\ Universitas PGRI Palembang \\ ${ }^{2,3}$ Dosen Program Studi Biologi, Fakultas Matematika dan Ilmu Pengetahuan Alam \\ Universitas PGRI Palembang \\ *e-mail : nadelaagitaria@yahoo.com
}

\begin{abstract}
This study aims to determine the effect of Monosodium Glutamate (MSG) on the growth of cayenne pepper plants (Capsicum frutescens L.). The research was carried out in March to May 2020 in Gedung Agung Village, Kota Agung Subdistrict, Lahat Regency, South Sumatra Province. The research method was using an experiment in a Completely Randomized Design (CRD), with 5 treatments and 4 replications. Doses used were P0 (without MSG / control), P1 (2 grams), P2 (4 grams), P3 (6 grams), P4 (8 grams). The parameters observed included stem diameter (cm), number of leaves (strands), stem height $(\mathrm{cm})$, and wet weight (grams). The results showed that monosodium glutamate significantly affected the growth of stem diameter, number of leaves, and stem height and did not significantly affect the growth of fresh weight of cayenne pepper plants. MSG concentration of 2 grams gave the highest yield of $0.8 \mathrm{~cm}$ for stem diameter growth. The highest number of leaves obtained as many as 14 leaves at a concentration of 2 grams of MSG. MSG concentration of 8 grams gave the highest yield to plant height of $35 \mathrm{~cm}$. In the growth of wet weight, the highest value was obtained by 2.2 grams on the addition of 6 grams of MSG.
\end{abstract}

Keywords: Monosodium Glutamate, Hot Pepper (Capsicum Frutescens L.), The Research Method Completely Randomized Design (RAL).

\begin{abstract}
ABSTRAK
Penelitian ini bertujuan untuk mengetahui pengaruh Monosodium Glutamate (MSG) terhadap pertumbuhan tanaman cabai rawit (Capsicum frutescens L.). Penelitian ini dilaksanakan pada bulan Maret sampai Mei 2020 di Desa Gedung Agung, Kecamatan Kota Agung, Kabupaten Lahat, Provinsi Sumatera Selatan.. Metode penelitian menggunakan eksperimen dalam Rancangan Acak Lengkap (RAL), dengan 5 perlakuan dan 4 ulangan. Dosis yang digunakan adalah P0 (tanpa msg/ kontrol), P1(2 gram), P2 (4 gram), P3 (6 gram), P4 (8 gram). Parameter yang diamati meliputi diameter batang $(\mathrm{cm})$, jumlah daun (helai), tinggi batang $(\mathrm{cm})$, dan berat basah (gram). Hasil penelitian menunjukkan bahwa monosodium glutamate berpengaruh nyata terhadap pertumbuhan diameter batang, jumlah daun, serta tinggi batang dan tidak berpengaruh nyata terhadap pertumbuhan berat basah tanaman cabai rawit. Konsentrasi MSG sebanyak 2 gram memberikan hasil tertinggi sebesar $0.8 \mathrm{~cm}$ untuk pertumbuhan diameter batang. Jumlah daun tertinggi diperoleh sebanyak 14 helai daun pada perlakuan konsentrasi sebesar 2 gram MSG. Konsentrasi MSG sebanyak 8 gram memberikan hasil tertinggi terhadap tinggi tanaman sebesar $35 \mathrm{~cm}$. Pada pertumbuhan berat basah, nilai tertinggi didapatkan sebesar 2.2 gram pada penambahan MSG sebanyak 6 gram.
\end{abstract}


Kata Kunci : Monosodium Glutamate (MSG), Cabai Rawit (Capsicum Frutescens L.), Metode Penelitian Rancangan Acak Lengkap (RAL).

\section{PENDAHULUAN}

Cabai merupakan tanaman famili solanaceae berasal dari benua Amerika tepatnya daerah Peru kemudian menyebar ke negara-negara benua Amerika, Eropa dan Asia termasuk negara Indonesia. Tanaman cabai memiliki banyak ragam tipe pertumbuhan dan bentuk buahnya. beberapa jenis tanaman cabai, yakni cabai besar, cabai merah, cabai keriting, cabai rawit dan paprika (Nurfalah, 2010 dalam Muswiatul et al., 2018).

Cabai rawit (Capsicum frutescens L.) salah satu jenis tanaman hortikultura yang biasa dibudidayakan komersial, cabai rawit memiliki kandungan gizi lengkap, memiliki nilai ekonomis tinggi banyak digunakan konsumsi rumah tangga maupun keperluan industri makanan (Nurlenawati et al., 2010).

Monosodium glutamate (MSG) terdiri $78 \%$ glutamate, $12 \%$ natrium dan $10 \%$ air. Senyawa larut dalam air. Kandungan kimia berperan menyuburkan tanaman. Tanpa natrium, tanaman tidak dapat meningkatkan kandungan air pada jaringan daun. Selain kandungan natrium, MSG juga mengandung asam amino. Peran asam amino untuk tanaman membantu pertumbuhan tanaman waktu muda (tunas) untuk merangsang agar daun lebih banyak, selain itu memberikan daya tahan terhadap hama dan penyakit. MSG juga mengandung unsur ion hydrogen apabila tercampur air menghasilkan gas yang dibutuhkan pertumbuhan akar dan batang (Pujiansyah et al., 2018).

\section{BAHAN DAN METODE}

\section{Alat dan Bahan}

Peralatan yang digunakan dalam penelitian yaitu bak benih, polybag, sekop tanah, jangka sorong, meteran/penggaris, kertas label, alat tulis, kamera digital dan timbangan. Sedangkan bahan yang digunakan yaitu MSG (Monosodium Glutamate) merk Ajinomoto, tanah, benih cabai rawit ( Capsicum frutescens L.).

\section{CARA KERJA}

\section{Persiapan penanaman cabai rawit}

a. Persiapan benih cabai rawit (Capsium frutescens L. ).

Benih yang dibeli di toko pertanian dengan membeli benih yang kualitas terbaik. Sebelum di tanam benih direndam dalam air selama 15 menit, benih yang mengapung dibuang, dan benih yang tenggelam digunakan untuk ditanam.

b.Persiapan penanaman bibit cabai rawit (Capsicum frutescens L.)

Bibit cabai yang diambil dari persemaian yang berumur $14 \mathrm{hst}$, dengan ukuran yang sama dipindahkan ke polibag. Dalam setiap polibag berisi 2 tanaman. Penanaman dilakukan pada sore hari untuk menghindari sinar matahari.

c.Penyulaman

Penyulaman dilakukan apabila terdapat tanaman yang mati atau pertumbuhannya kurang baik, dan bibit pengganti harus subur pertumbuhannya serta masih seumuran dengan tanaman yang akan diganti atau sisa bibit semai. Penyulaman akan dilakukan 3-5 hari setelah penanaman.

d.Pemeliharaan tanaman cabai rawit

Pemeliharan tanaman meliputi penyiraman dan membersikan tanaman dari gulma.

e.Persiapan media tanam

Media yang digunakan yaitu media tanah. Tanah dimasukkan kedalam polibag yang memiliki ukuran diameter 21 $\mathrm{cm}$ dan tinggi $30 \mathrm{~cm}$. Kemudian di isi 
dengan tanah sebanyak $1 \mathrm{~kg}$ dan menanam tanaman cabai rawit sebanyak 3 batang dalam satu polibag. Polibag disusun dengan tata letak unit percobaan.

f.Pemberian MSG

Pemberian monosodium glutamate pada tanaman cabai saat berumur 1 minggu setelah dipindahkan ke polibag.
Monosodium glutamate ditaburkan disekitar batang tanaman cabai sesuai dengan dosis masing - masing pada

setiap perlakuan. Pemberian MSG dilakukan 14 hst, dan 28 hst.

\section{HASIL DAN PEMBAHASAN}

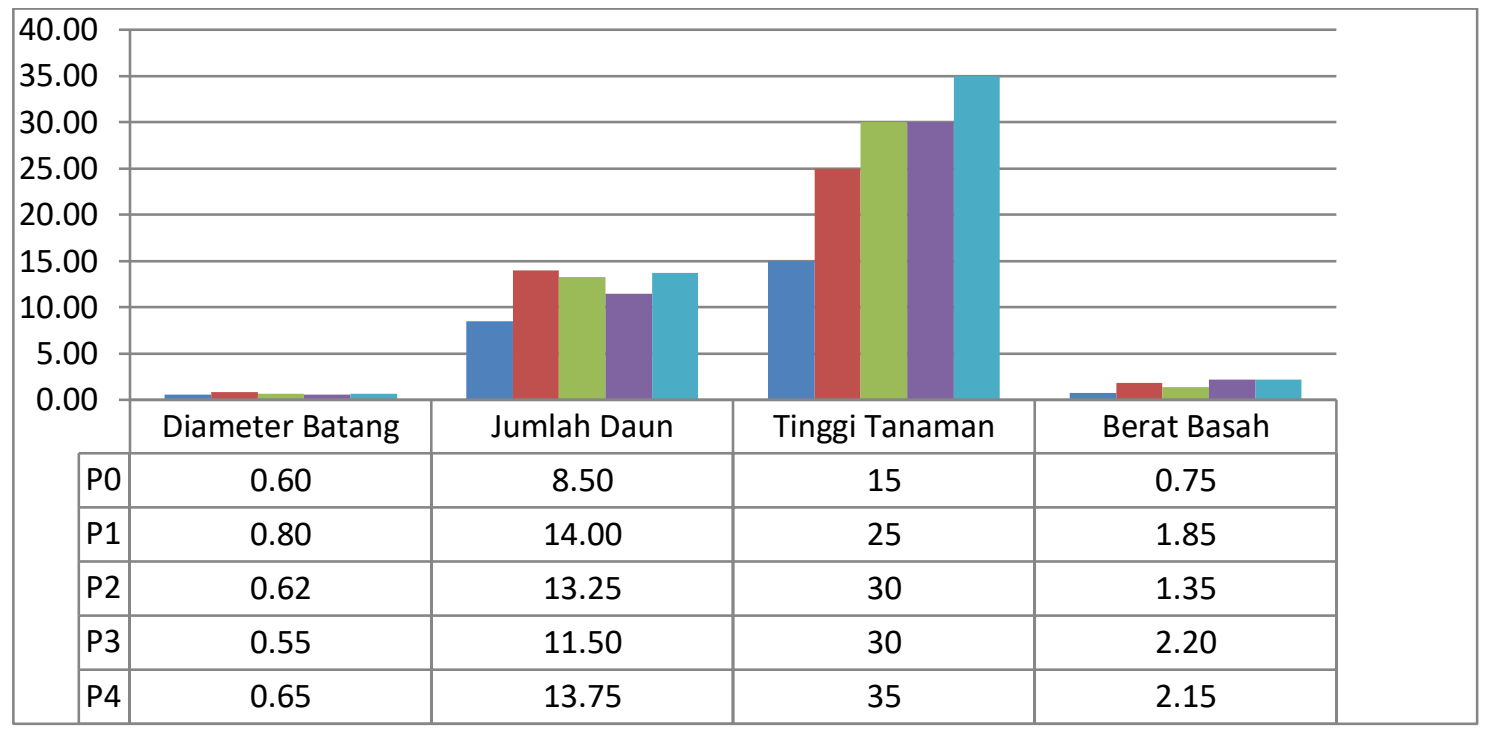

Gambar 2. Grafik nilai rata - rata pengaruh pertumbuhan diameter batang, jumlah daun, tinggi tanaman, berat basah tanaman cabai rawit yang diberikan MSG

Analisis Sidik Ragam terhadap perbedaan nyata terhadap diameter Diameter Batang Cabai Rawit (Capsium frutenscens L.) yang mendapat perlakuan MSG batang, Hal ini dapat dilihat pada Tabel 2

Perlakuan yang diberikan terhadap cabai rawit secara statistik menunjukan

Tabel 2. Hasil Analisis Sidik Ragam Pengaruh Pemberian MSG terhadap Diameter Batang Cabai Rawit (Capsium frutenscens L.)

\begin{tabular}{lllllr}
\hline $\begin{array}{l}\text { Sumber } \\
\text { Keragaman }(\text { SK })\end{array}$ & $\begin{array}{l}\text { Derajat Bebas } \\
(\text { DB })\end{array}$ & $\begin{array}{l}\text { Jumlah } \\
\text { Kuadrat (JK) }\end{array}$ & $\begin{array}{l}\text { Kuadrat Tengah } \\
(\text { KT })\end{array}$ & F $_{\text {hitung }}$ & F tabel
\end{tabular}

\begin{tabular}{lccccc}
\hline Perlakuan & 4 & 0.14 & 0.035 & 7 & 2.77 \\
Eror $(\mathrm{g})$ & 15 & 0.07 & 0.005 & & \\
Total & 19 & 0.21 & & & \\
\hline
\end{tabular}

Keterangan :berpengaruh nyata 
Berdasarkan hasil ANSIRA pada Tabel 2 pengaruh pertumbuhan diameter batang, didapat bahwa $\mathrm{F}_{\text {hitung }} 7>\mathrm{F}_{\text {Tabel }}$ 2,77, yang artinya perlakuan pemberian MSG berpengaruh nyata terhadap pertumbuhan diameter batang pada tanaman cabai rawit. Selanjutnya dilakukan uji BNT dan hasilnya dapat dilihat pada Tabel 3 berikut:

Tabel 3. Uji BNT terhadap Diameter Batang Cabai Rawit

\begin{tabular}{cc}
\hline Perlakuan & Rata-rata \\
\hline P0 & $0.6 \mathrm{a}$ \\
P1 & $0.8 \mathrm{~b}$ \\
P2 & $0.62 \mathrm{~b}$ \\
P3 & $0.55 \mathrm{~b}$ \\
P4 & $0.65 \mathrm{c}$ \\
\hline
\end{tabular}

BNT $5 \%=0.062$

Keterangan :Huruf yang sama artinya tidak berbeda nyata dan huruf yang berbeda berarti berbeda nyata

Dari Tabel di atas, dapat dilihat bahwa perlakuan $\mathrm{P} 0$ berbeda tidak nyata dengan perlakuan P1( 2 gram MSG), P2 (4 gram MSG), P3( 6 gram MSG), P4 (8 gram MSG). Pada perlakuan P1 memberikan hasil rata- rata tertinggi dan terendah pada $\mathrm{P} 3$.

\section{Analisis Sidik Ragam terhadap Jumlah daun Tanaman Cabai Rawit (Capsium frutenscens L.) yang mendapatkan perlakuan MSG}

Perlakuan yang diberikan terhadap cabai rawit secara statistik menunjukan perbedaan nyata terhadap diameter batang, Hal ini dapat di lihat pada Tabel 4 Berikut :

Tabel 4. Hasil Analisis Sidik Ragam Pengaruh Jumlah Daun Cabai Rawit (Capsium frutenscens L.) terhadap Pemberian MSG

\begin{tabular}{lccccc}
\hline $\begin{array}{l}\text { Sumber } \\
\text { Keragaman } \\
(\text { SK })\end{array}$ & $\begin{array}{l}\text { Derajat Bebas } \\
\text { ( DB) }\end{array}$ & $\begin{array}{l}\text { Jumlah } \\
\text { Kuadrat (JK) }\end{array}$ & $\begin{array}{l}\text { Kuadrat } \\
\text { Tengah (KT) }\end{array}$ & F $_{\text {hitung }}$ & F tabel \\
\hline Perlakuan & 4 & 0.098 & 0.024 & 5.85 & 2.77 \\
Eror $(\mathrm{g})$ & 15 & 0.062 & 0.0041 & & \\
Total & 19 & 0.16 & & & \\
\hline
\end{tabular}

Keterangan :berpengaruh nyata

Berdasarkan hasil ANSIRA di atas pengaruh pertumbuhan tinggi tanaman cabai rawit, di dapat hasil bahwa $F_{\text {hitung }}$ $5.85>\mathrm{F}_{\text {tabel }} 2.77$, yang artinya perlakuan pemberian MSG memberikan pengaruh nyata terhadap pertumbuhan tinggi tanaman cabai. Selanjutnya dilakukan uji BNT dan hasinya dapat dilihal pada Tabel 5 berikut : 
Tabel 5. Uji BNT Pengaruh Pemberian MSG terhadap Jumlah Daun Cabai Rawit

\begin{tabular}{cc}
\hline Perlakuan & Rata -rata \\
\hline P0 & $8.5 \mathrm{a}$ \\
P1 & $14 \mathrm{~b}$ \\
P2 & $11.5 \mathrm{bc}$ \\
P3 & $11.5 \mathrm{bc}$ \\
P4 & $13.75 \mathrm{~b}$ \\
\hline
\end{tabular}

BNT 5\%:0,64

Keterangan : Huruf yang sama artinya tidak berbeda nyata dan huruf yang berbeda artinya berbeda nyata

Dari Tabel 5,terlihat perlakuan P0 (tanpa pemberian MSG/ kontrol) berbeda nyata dengan perlakuan P1 (2 gram MSG ), P2 (4 gram MSG), P3 (6 gram MSG), P4 (8 gram MSG). ini berarti hasil yang tertinggi untuk parameter pertumbuhan jumlah daun cabai rawit diperoleh pada perlakuan P2 (4 gram MSG).

\section{Analisis Sidik Ragam terhadap Tinggi Tanaman Cabai Rawit (Capsium frutenscens $\mathrm{L}$.) yang mendapatkan perlakuan MSG}

Perlakuan yang diberikan terhadap cabai rawit, dari analisis sidik ragam secara statistik menunjukan perbedaan nyata terhadap tinggi tanaman, Hal ini dapat dilihat pada Tabel 6 berikut :

Tabel 6. Hasil Analisis Sidik Ragam Pengaruh Tinggi Batang Cabai Rawit (Capsium frutenscens L.) terhadap pemberian MSG

\begin{tabular}{lccccc}
\hline $\begin{array}{l}\text { Sumber } \\
\text { Keragaman } \\
(\text { SK })\end{array}$ & $\begin{array}{l}\text { Derajat } \\
\text { Bebas( DB) }\end{array}$ & $\begin{array}{l}\text { Jumlah } \\
\text { Kuadrat (JK) }\end{array}$ & $\begin{array}{l}\text { Kuadrat } \\
\text { Tengah (KT) }\end{array}$ & F hitung & Ftabel \\
\hline Perlakuan & 4 & 58388.8 & 36471.95 & 11.44 & 2.77 \\
$\begin{array}{l}\text { Eror }(\mathrm{g}) \\
\text { Total }\end{array}$ & 15 & 4778.4 & 3.186 .5 & & \\
\hline
\end{tabular}

Keterangan : berpengaruh nyata

Tabel .7. Uji BNT Pengaruh Pemberiaan MSG terhadap Tinggi Tanaman Cabai Rawit

\begin{tabular}{cc}
\hline Perlakuan & Rata -rata \\
\hline P0 & $15 \mathrm{a}$ \\
P1 & $25 \mathrm{~b}$ \\
P2 & $30 \mathrm{bc}$ \\
P3 & $30 \mathrm{bc}$ \\
P4 & $35 \mathrm{~d}$ \\
\hline
\end{tabular}

BNT 5\%:9.4

Keterangan : Huruf yang sama artinya tidak berbeda nyata dan huruf yang berbeda berarti berbeda nyata.

Dari Tabel 7, dapat dilihat perlakuan P0 (tanpa pemberian MSG/ kontrol) berbeda nyata dengan perlakuan P1 (2 gram MSG), P2 (4 gram MSG), P3 (6 gram MSG), P4 (8 gram MSG). Hasil tertinggi diperoleh pada perlakuan $\mathrm{P} 4$ (8 gram MSG).

\section{Analisis Sidik Ragam terhadap Berat Basah Cabai Rawit (Capsium frutenscens L.) yang mendapatkan MSG \\ Perlakuan yang diberikan terhadap cabai rawit secara statistik menunjukan perbedaan nyata terhadap diameter}


batang, hal ini dapat di lihat pada Tabel 8

berikut :

Tabel 8. Hasil Analisis Sidik Ragam Pengaruh Berat Basah Cabai Rawit (Capsium frutenscens L.) terhadap Pemberian MSG

\begin{tabular}{llcccc}
\hline $\begin{array}{l}\text { Sumber } \\
\text { Keragaman } \\
(\text { SK) }\end{array}$ & $\begin{array}{l}\text { Derajat } \\
\text { Bebas } \\
\text { (DB) }\end{array}$ & $\begin{array}{l}\text { Jumlah } \\
\text { Kuadrat } \\
(\text { JK) }\end{array}$ & $\begin{array}{l}\text { Kuadrat } \\
\text { Tengah }(K T)\end{array}$ & $\mathbf{F}_{\text {hitung }}$ & $\mathbf{F}_{\text {tabel }}$ \\
\hline Perlakuan & 4 & 1.2 & 0.28 & 0.8 & 2.77 \\
Eror (g) & 15 & 5.2 & 0.35 & & \\
Total & 19 & 6.3 & & & \\
\hline
\end{tabular}

Keterangan: berpengaruh tidak nyata

Berdasarkan hasil Analisis Sisik Ragam (ANSIRA) pada Tabel 8 pertumbuhan berat basah pada tanaman cabai didapatkan $\mathrm{F}_{\text {hitung }} 0.8<\mathrm{F}_{\text {tabel }} 2.77$, yang artinya pemberian MSG memberikan pengaruh tidak nyata terhadap pertumbuhan berat basah pada tanaman cabai rawit.

\section{PEMBAHASAN}

Hasil yang didapatkan dari pengukuran dapat dilihat pada Tabel 2,Tabel 4, dan Tabel 6 bahwa MSG memberikan pengaruh nyata pada tanaman cabai rawit yang dapat meningkatkan tinggi batang, jumlah daun dan diameter batang. Semakin tinggi dosis MSG diberikan semakin bertambah tinggi batang. Namun diameter batang, dan jumlah daun menunjukan hasil yang bervariasi (Tabel 2 dan tabel 4). Sementara itu untuk hasil berat basah menunjukan pengaruh tidak nyata (Tabel 8).

Pada perlakuan P1 memberikan hasil yang terbaik untuk parameter, hal ini menunjukan bahwa dosis 2 Gram efektif untuk pertumbuhan sel kearah lateral diameter batang bertambah. Pertumbuhan sel kearah lateral berarti menambah sel sel pada jaringan xilem, floem,itu artinya bahwa giberelin yang terkandung dalam MSG bekerja memiju keanekaragaman fungsi sel. Menurut Panji, (2008) dalam Pujiansyah et al.,( 2018) MSG diduga mempunyai kandungan yang berperan sebagai hormon perangsang tumbuh seperti giberelin yang berfungsi untuk memacu keanekaragaman fungsi sel sehingga sel yang awalnya diarahkan untuk pertumbuhan tunas daun dapat dialihkan untuk pertumbuhan tunas bunga, dan pertumbuhan diameter pada suatu batang tanaman.

Pemberian 2 gr MSG (Perlakuan pada P1) memberikan pengaruh terbaik untuk jumlah daun. hal ini terjadi karena Nitrogen yang terkandung dalam MSG dapat meningkatkan pertumbuhan vegetatif, terutama pada pertumbuhan daun, Nitrogen juga dapat mempercepat pertumbuhan vegetatif, dan meningkatkan jumlah daun (Dinda et al., 2019).

Pemberian MSG sebanyak 8 gr (perlakuan P4) meningkatkan tinggi rata rata 35 lebih tinggi dari pada perlakuan $\mathrm{P} 0, \mathrm{P} 1, \mathrm{P} 2, \mathrm{P} 3$, pertumbuhan tinggi terlihat pada saat memasuki minggu ke 3 , Hal ini menunjukan pemanfaatan $\mathrm{N}$ yang terkandung dalam MSG mempengaruhi pertumbuhan pada tinggi tanaman saat memasuki minggu ke 3, Nitrogen sebagai salah satu unsur makro yang berfungsi meningkatkan tinggi tanaman (Febri et al., 2018

Berat basah pada tanaman cabai rawit tidak berpengaruh nyata pada setiap 
perlakuan, (hasil tidak berbeda nyata). Ini merupakan pemberian MSG tidak menyebabkan perbedaan kecukupan air dan lebih dari hasil fotosintesis, lingkungan, seperti suhu dan kelembaban udara dapat mempengaruhi keadaan air yang terkandungnya dalam sel - sel tanaman. Sehingga dapat mempengaruhi berat basah ( Sitompul et al.,1995 dalam Indri et al., 2007.)

\section{KESIMPULAN}

Kesimpulan yang didapat dari hasil penelitian ini yaitu monosodium glutamate (MSG) pengaruh nyata terhadap pertumbuhan diameter batang, jumlah daun, dan tinggi tanaman dan tidak berpengaruh nyata pada berat basah tanaman cabai rawit (Capsicum frutescens L.).

\section{DAFTAR PUSTAKA}

Dinda, V. B., Latifah S. 2019. MSGManfaat Micin Untuk Tanaman Padi (Mantap) Sebagai Pangan Yang Bebas Bahan Kimia Dan Ramah Lingkungan Guna Menjaga Kesehatan Masyarakat Menuju Indonesia Berkemajuan. Prosiding Seminar Nasional Lahan Suboptimal. :504 - 505.

Febri, D. M. 2018. Respon Tanaman Kacang Tanah (Arachis Hypogea L.) Pada Berbagai Aplikasi Pupuk $\mathrm{N}$ dan Kompos Azolla. Jurnal Produksi Tanaman. 6(5): 791 800.

Indri, I., Rini ,B,H.,Sri H. 2007. Pengaruh Perasaan Sargassum crassifolium dengan Konsentrasi yang Berbeda terhadap Pertumbuhan Tanaman Kedelai. Buletin Anatomi dan Fisiologi. XV(2007) :11-12.

Kartikasar, D. N., S. L. Purnamaningsih, dan L. Soetopo. 2016. Penampilan
Galur Generasi Pertama Hasil Seleksi Dari Cabai Rawit (Capsicum frutescens L.) Varietas Lokal. Jurnal Produksi Tanaman. 4(4): $320-324$.

Muswiatul, J., A. R. Dharmawan, dan I. R. Safitri. 2018. Pemberian Monosodium Glutamate pada Tanaman dan Potensinya dalam Mempengaruhi Pertumbuhan Cabai. Seminar Nasional. Vol. IV: 207-212.

Pujiansyah., W.D. Ully Parwati. E Rahayu. 2018. Pengaruh Monosodium Glutamat sebagai Pupuk. Alternatif serta Cara Pemberiannya terhadap Pertumbuhan Bibit Kelapa Sawit Pre Nursery. Jurnal Agromast. (3) $1: 2-3$. 